\title{
Comparative study of the endotoxin-stimulated nitroblue tetrazolium test in disease and health
}

\author{
N. HAIM, N. OBEDEANU, T. MESHULAM, E. ROBINSON, E. BEN-LAYISH, \\ AND D. MERZBACH
}

From the Departments of Oncology and Microbiology, Rambam Medical Centre and Aba Khoushy School of Medicine, Haifa, Israel

SUMMARY Endotoxin-stimulated nitroblue tetrazolium (NBT) reduction was evaluated in 853 individuals: 270 healthy controls, 334 with various non-neoplastic conditions, 220 with solid non-lymphomatous tumours, and 29 with lymphoma. Each of the above groups was divided into three age subgroups: $<60,60-69$, and $\geqslant 70$ years.

In the controls and in patients with nonmalignant diseases, significantly lower values were recorded for elderly subjects $(\geqslant 60$ years) compared with younger subjects of the same group, whereas in cancer patients the results were independent of age. Under the age of 60 , stimulated values for both patient groups were significantly lower than the control values, and in patients with solid non-lymphomatous tumours significantly lower values were attained than in the other patients. NBT reduction in lymphoma patients was comparable to that of the controls. In the elderly (age $\geqslant$ 70) no significant differences were noted between patients and controls.

It is suggested that stimulated NBT reduction declines with advancing age. While this test clearly demonstrates some leucocyte dysfunction in solid cancer, its value in investigating neutrophil behaviour in elderly subjects is questioned.

According to recent observations made in our laboratory, peripheral polymorphonuclear leucocytes (PMNs) from patients with solid cancer have a diminished capacity to reduce nitroblue tetrazolium (NBT) dye to formazan when maximally stimulated with endotoxin (Haim et al., 1977a, 1977b). This impaired leucocytic reactivity was found in both treated and untreated patients, in patients with active malignancy, as well as in cured cancer patients.

The above findings prompted us to conduct a comparative study of endotoxin-stimulated NBT reduction values in relatively large groups of patients with cancer, in patients with a variety of non-malignant conditions, and in healthy subjects. Special emphasis was given to possible age variations in the results.

\section{Subjects}

A total of 853 individuals were tested for the endotoxin-stimulated NBT reduction. The investigated population was divided into the following groups:

Received for publication 15 June 1978
HEALTHY CONTROLS

This group consisted of 270 healthy medical personnel, relatives of patients, and old people living in a home for the aged. Included were 142 women and 128 men aged 19 to 88 years. Subjects with acute illnesses and those receiving anti-inflammatory drugs were excluded. The presence of degenerative disorders, such as atherosclerotic cardiovascular diseases, or osteoarthritis in aged subjects, did not preclude participation in the study.

\section{HOSPITAL INPATIENTS WITH}

NON-NEOPLASTIC CONDITIONS

There were 334 inpatients from the internal, surgical, gynaecological, and rheumatological departments of our hospital; 136 were women and 198 men, and their ages ranged from 16 to 89 years. None of these patients had a diagnosis of malignant disorder. Otherwise they were unselected and presented with a wide spectrum of diseases.

\section{PATIENTS WITH NON-LYMPHOMATOUS}

SOLID TUMOURS (CANCER PATIENTS)

A total of 220 patients, 139 women and 81 men, 16 to 81 years old, with various types of solid cancer were investigated. The following criteria 
were used for patients' selection into this group: absence of prior chemotherapy or radiotherapy, absence of infection or other intercurrent disease, postoperative interval of at least three weeks, and absence of treatment with corticosteroids or other anti-inflammatory agents known to alter PMN metabolism.

\section{LYMPHOMA PATIENTS}

Included were 29 patients, six with Hodgkin's disease and 23 with non-Hodgkin's lymphoma. There were 11 women and $18 \mathrm{men}$, and their ages ranged between 19 and 59 years. Eligibility criteria were similar to those in the group of cancer patients.

\section{Methods}

All investigated groups were concurrently studied. The endotoxin-stimulated NBT reduction tests were performed between 30 minutes and two hours after blood collection, according to the technique of Park and Good (1970), as modified by Merzbach and Obedeanu (1975). All tests were performed in two parallel aliquots of the blood samples and treated identically. Leucocyte stimulation was achieved with $20 \mu \mathrm{g} / \mathrm{ml}$ of Escherichia coli $055: \mathrm{B} 5$ lipopolysaccharide (Difco Laboratories, Detroit, Mich, USA). The counting of NBT-positive neutrophilic leucocytes was performed without any prior information as to the source of the sample.

Inter-group calculations of significance were made according to Mann Whitney's rank sum test; P-values exceeding 0.05 were regarded as not significant.

\section{Results}

The control group revealed age-related differences in NBT scores. This age dependence was evident only over the age of 60 and became more pronounced after the age of 70 years. Consequently, all investigated groups of subjects were subdivided into three age subgroups, that is, up to 59 years, 60 to 69 years, and 70 years or over.

The results obtained are summarised in the Table. As the Table reveals, the NBT reduction in the controls gradually decreased with age. There were statistically significant differences between the age subgroups of 60 to 69 and that over $70(\mathrm{P}<0.015)$ and also between these two subgroups and that under 60 years. A similar trend of age-related decrease can also be seen in the group of patients with non-malignant diseases, although the differences in the values between subgroups $60-69$ and over 70 were not statistically significant. In cancer patients, however, the mean values in all age-subgroups were very close to each other.

In cancer patients and in patients with non-malignant diseases under the age of 60 , the values recorded were significantly lower than those in the control group of corresponding age, whereas in patients with lymphoma they were similar to those of the controls. Cancer patients aged under 60 showed significantly lower values than those of age-corresponding patients with non-neoplastic diseases $(\mathrm{P}<0.0005)$ and those with lymphoma $(\mathrm{P}<0.0005)$.

A separate analysis was made for 56 cancer patients under 60 years of age who were clinically free of disease at the time of testing. The scores in this group (average 30.62 \pm 1.65 ; range 7-64) were also significantly lower than those of the controls $(P<0.0005)$.

In the age subgroup of $60-69$ years, the values recorded in patients with non-malignant disorders were not significantly lower than in the agecorresponding controls' subgroup. However, cancer

Table Stimulated NBT test results in patients and controls

\begin{tabular}{|c|c|c|c|c|c|c|c|}
\hline \multirow[t]{2}{*}{ Group } & \multirow[t]{2}{*}{ Age subgroup } & \multirow[t]{2}{*}{ Number of cases } & \multicolumn{3}{|c|}{ Stimulated NBT reduction ( $\% N B T$-positive $P M N s$ ) } & \multicolumn{2}{|c|}{$P$ value compared to: } \\
\hline & & & $M e a n \pm S E M$ & Median & Range & $\begin{array}{l}\text { Age-matched } \\
\text { control group }\end{array}$ & $\begin{array}{l}\text { Youngest age } \\
\text { subgroup }\end{array}$ \\
\hline $\begin{array}{l}\text { Healthy } \\
\text { controls }\end{array}$ & $\begin{array}{r}\leqslant 59 \\
60-69 \\
\geqslant 70\end{array}$ & $\begin{array}{r}195 \\
39 \\
36\end{array}$ & $\begin{array}{l}42.74 \pm 0.84 \\
36.97 \pm 2.32 \\
32.03 \pm 1.98\end{array}$ & $\begin{array}{l}44 \\
36 \\
32 \cdot 5\end{array}$ & $\begin{array}{r}11-68 \\
7-68 \\
7-57\end{array}$ & & $\begin{array}{l}0.0075 \\
0.0005\end{array}$ \\
\hline $\begin{array}{l}\text { Patients } \\
\text { with non- } \\
\text { malignant } \\
\text { diseases }\end{array}$ & $\begin{array}{r}\leqslant 59 \\
60-69 \\
\geqslant 70\end{array}$ & $\begin{array}{r}197 \\
73 \\
64\end{array}$ & $\begin{array}{l}37.6 \pm 1.08 \\
34.58 \pm 1.71 \\
31.18 \pm 1.07\end{array}$ & $\begin{array}{l}38 \\
32 \\
28 \cdot 5\end{array}$ & $\begin{array}{l}6-75 \\
4-77 \\
3-71\end{array}$ & $\begin{array}{l}0.0005 \\
\text { NS* } \\
\text { NS }\end{array}$ & $\begin{array}{l}0.036 \\
0.0015\end{array}$ \\
\hline $\begin{array}{l}\text { Cancer } \\
\text { patients }\end{array}$ & $\begin{array}{r}\leqslant 59 \\
60-69 \\
\geqslant 70\end{array}$ & $\begin{array}{r}129 \\
54 \\
37\end{array}$ & $\begin{array}{l}29.66 \pm 1 \cdot 18 \\
28.81 \pm 1.85 \\
30.97 \pm 2.22\end{array}$ & $\begin{array}{l}30 \\
29 \\
30\end{array}$ & $\begin{array}{l}2-82 \\
5-62 \\
9-64\end{array}$ & $\begin{array}{l}0.0005 \\
0.008 \\
\text { NS }\end{array}$ & $\begin{array}{l}\text { NS } \\
\text { NS }\end{array}$ \\
\hline $\begin{array}{l}\text { Lymphoma } \\
\text { patients }\end{array}$ & $\leqslant 59$ & 29 & $39 \cdot 41 \pm 2.63$ & 42 & $8-71$ & NS & \\
\hline
\end{tabular}

* Not significant 
patients of this age subgroup showed significantly lower values than both healthy controls $(\mathrm{P}<0.008)$ and patients with non-malignant disorders $(P<$ 0.030).

In the old age subgroup of 70 years or more, no significant differences were noted between patients and controls.

The ranges of the stimulated reduction scores varied within wide limits in all subgroups of investigated subjects. The lower value for 195 healthy subjects aged under 60 years was $11 \%$. Scores below this limit were obtained in 10 out of 129 cancer patients $(8 \%)$ and in only five out of 197 $(2 \cdot 5 \%)$ age-corresponding patients with non-neoplastic disorders.

\section{Discussion}

Stimulated NBT reduction by several agents, such as live and inert particles or by the more commonly used endotoxin, has proved useful in detecting leucocyte dysfunction in a variety of pathological conditions, such as chronic granulomatous disease (Baehner and Nathan, 1968), malignant processes (Humbert et al., 1976; Haim et al., 1977a, 1977b), and others (Shousha and Kamel, 1972; Curreri et al., 1973; Gray et al., 1973; Tan et al., 1973). Our study, however, reveals that the validity of this test in studying leucocyte abnormalities in advanced age is questionable since the difference in the reduction capacity between disease and health becomes blurred in old subjects.

The effect of age on PMNs' function is as yet inconclusive. Kauffman et al. (1977) reported a decreased bactericidal capacity of leucocytes in elderly subjects. Eschenbach et al. (1975), on the other hand, found that the capacity of NBT reduction of neutrophils is independent of age. An analysis of the values of endotoxin-stimulated NBT reduction in the present group of healthy control subjects clearly demonstrated that stimulated NBT reduction capacity declines with advancing age, especially over 70 years. It is noteworthy that various parameters of cell-mediated immunity are also known to be depressed in old subjects (Roberts-Thomson et al., 1974).

A similar age-related reduction capacity, though less pronounced, was also noted in the group of patients with non-malignant diseases. On the other hand, no such relationship was evident in cancer patients. Perhaps in these patients the ability of leucocytes to reduce NBT is already depressed by the underlying disease, and no further agerelated depression could be expected.

NBT reduction in cancer patients was obviously lower than in the group of patients with nonmalignant diseases. In accordance with our previous studies (Haim et al., 1977a, 1977b), the present study also showed a diminished reduction capacity in cancer patients, who were clinically free of tumour at the time of testing. It is worth noting that leucocyte alkaline phosphatase (LAP) activity was also found to be decreased in patients with solid tumours who had no evidence of disease when studied (Lokich, 1977).

An enhanced spontaneous NBT reduction and phagocyte killing capacity has been frequently reported in patients with lymphoma (Silverman and Reed, 1973; Chang et al., 1974; Hancock et al., 1976; Steigbigel et al., 1976). In our study, the capacity of reduction in these cases was comparable to that in healthy controls and markedly higher than in patients with other solid tumours. It seems, therefore, that malignant lymphoma differs from non-lymphomatous malignancy with regard to stimulated NBT reduction.

The individual variation in healthy controls was great (range $11-68 \%$ in subjects under 60 ). Hence, the lower limit below which the stimulated NBT score should be considered pathological is as yet undetermined, and the test cannot serve as a quantitative indicator of PMNs' function in individual patients.

\section{References}

Baehner, R. L., and Nathan, G. D. (1968). Quantitative nitroblue tetrazolium test in chronic granulomatous disease. New England Journal of Medicine, 278, 971-976.

Chang, J. C., Appleby, J., and Bennett, J. M. (1974). Nitroblue tetrazolium test in Hodgkin disease and other malignant lymphomas. Archives of Internal Medicine, 133, 401-403.

Curreri, P. W., Heck, E. L., Browne, L., and Baxter, C. R. (1973). Stimulated nitroblue tetrazolium test to assess neutrophil anti-bacterial function: prediction of wound sepsis in burned patients. Surgery, 74, 6-13.

Eschenbach, C., Seebach, G., and Müller-Lassner, St. (1975). Nitroblau-Tetrazolium-Reduktionskapazität von neutrophilen Granulocyten. Klinische Wochenschrift, 53, 1049-1056.

Gray, G. R., Klebanoff, S. J., Stamatoyannopoulos, G., Austin, T., Naiman, S. C., Yoshida, A., Kliman, M. R., and Robinson, G. C. F. (1973). Neutrophil dysfunction, chronic granulomatous disease, and non-spherocytic haemolytic anaemia caused by complete deficiency of glucose-6-phosphate dehydrogenase. Lancet, 2, 530-534.

Haim, N., Obedeanu, N., Meshulam, T., Robinson, E., and Merzbach, D. (1977a). Spontaneous and stimulated nitroblue tetrazolium tests of leukocytes from patients with solid malignant tumors. American Journal of Clinical Pathology, 68, 570-574. 
Haim, N., Obedeanu, N., Meshulam, T., Robinson, E., Schreiber, H., and Merzbach, D. (1977b). Neutrophil function in cured cancer patients. Cancer, 40, 2273-2277.

Hancock, B. W., Bruce, L., and Richmond, J. (1976). Neutrophil function in lymphoreticular malignancy. British Journal of Cancer, 33, 496-500.

Humbert, J. R., Hutter, J. J., Jr., Thoren, C. H., and DeArmey, P. A. (1976). Decreased neutrophil bactericidal activity in acute leukemia of childhood. Cancer, 37, 2194-2200.

Kauffman, C., Bjornson, A., and Phair, J. (1977). Age, host defenses, and pharyngeal acquisition of nosocomial flora. Clinical Research, 25, 378A.

Lokich, J. J. (1977). Leukocyte alkaline phosphatase activity in patients with malignant disease. Cancer, 40, 1202-1205.

Merzbach, D., and Obedeanu, N. (1975). Standardisation of the nitroblue-tetrazolium test. Journal of Medical Microbiology, 8, 375-384.

Park, B. H., and Good, R. A. (1970). N.B.T. test stimulated (Letter). Lancet, 2, 616.

Roberts-Thomson, I. C., Whittingham, S., Youngchaiyud,
U., and Mackay, I. R. (1974). Ageing, immune response, and mortality. Lancet, 2, 368-370.

Shousha, S., and Kamel, K. (1972). Nitroblue tetrazolium test in children with kwashiorkor with a comment on the use of latex particles in the test. Journal of Clinical Pathology, 25, 494-497.

Silverman, E. M., and Reed, R. E. (1973). The nitroblue tetrazolium test in lymphoma. American Journal of Clinical Pathology, 60, 198-201.

Steigbigel, R. T., Lambert, L. H., Jr., and Remington, J. S. (1976). Polymorphonuclear leukocyte, monocyte and macrophage bactericidal function in patients with Hodgkin's disease. Journal of Laboratory and Clinical Medicine, 88, 54-62.

Tan, C. V., Rosner, F., and Feldman, F. (1973). Nitroblue tetrazolium dye reduction in various hematologic disorders. New York State Journal of Medicine, 73, 952-956.

Requests for reprints to: Dr N. Haim, Department of Oncology, Rambam Medical Center, Aba Khoushy School of Medicine, Haifa, Israel. 